\title{
A consistência democrática na Venezuela em tempos de mudança política
}

\author{
Valia Pereira Almao \\ Instituto de Estudos Políticos e Direito Público \\ Universidade de Zulia, Venezuela
}

\begin{abstract}
Resumo
Este artigo analisa a preferência democrática e sua consistência nas atitudes dos venezuelanos entre 1995 e 2000, com base em dados provenientes de pesquisas nacionais. As tendências históricas da atitude democrática são consideradas a partir de características sócio-demográficas, políticas e ideológicas, e sua consistência é analisada segundo o apoio que teria um governo militar ou um líder forte, e a partir da análise da simpatia partidária. Em todos esses aspectos, obtêm-se incongruências com os elevados índices de aceitação da democracia apresentados, o que permite estabelecer a presença de predisposições autoritárias que, se estimuladas, poderiam reduzir no tempo o valor que a democracia tem para os venezuelanos.
\end{abstract}

Palavras-chave: atitudes políticas, democracia, cultura política, política venezuelana.

\section{Abstract}

This article analyses the democratic preference and its consistency among the attitudes of Venezuelans between 1995 and 2000. Data come from national survey research data, and the historical trends of democratic attitudes are analysed based on sociodemographic, political and ideological aspects. The consistency of democratic attitudes is analysed based on the support to military regimes and strong leadership, and also based on party preference. One observes incongruences among the high levels of democratic support and those variables, what suggests a predisposition to authoritarian support.

Key words: political attitudes, democracy, political culture, venezuelan politics. 
ALMAO, V. P. A consistência democrática na Venezuela em tempos de mudança política

Introdução

Depois que o sistema democrático foi consolidado na Venezuela e foram superados os riscos desestabilizadores da década de 1960, a preferência pela democracia tem sido um valor apreciado pelos venezuelanos.

Após alguns anos de ampla estabilidade, foi desencadeada uma crise política em 1989, traduzida em duas tentativas de golpe em 1992. O sistema partidário, uma das bases importantes para a consolidação democrática, chega decadente e rumo à sua extinção no final da década de 1990 e, em 1998, os partidos tradicionais perdem o controle sobre boa parte dos eleitores, como já havia acontecido em 1993 com a eleição de Rafael Caldera. Mais uma vez, líderes pessoais e novos partidos eleitorais disputam com a AD (Aliança Democrática) e o COPEI (Comitê de Organização Política Eleitoral Independente) a supremacia na arena política. Surgem os partidos Movimento $V$ República (MVR) e Projeto Venezuela (PV), com candidatos próprios, e um militar reformado, líder de uma das tentativas golpistas de 1992, atinge a presidência. Em 1998, as simpatias partidárias dividem-se majoritariamente entre esses dois partidos e a AD e o COPEI tornam-se partidos minoritários.

Sob o marco da desinstitucionalização partidária é possível que as mudanças de preferência partidária incidam no apreço à democracia. A nova estrutura de partidos é frágil, sem o enraizamento substancial na população que ocorre a longo prazo, e sem regras claras de entrada na arena política, traços que não contribuem para a estabilidade democrática (HUNTINGTON, 1965; DIX, 1992; MAINWARING e SCULLY, 1995; MAINWARING, 1999; MOLINA, 1998 e 2000). Que força democrática podem ter os partidos que se iniciam no jogo democrático? Quanto terão se beneficiado da exposição prévia ao sistema democrático os que hoje constituem os novos partidos? Sendo a preferência democrática tão alta em 2000, por que se deve temer essas incógnitas? Essas são incógnitas complexas, mas é preciso resolvê-las. Assim, adquire pertinência uma análise das características da atitude e da consistência democráticas em 2000, de forma a frear as atitudes autoritárias, em especial as militaristas, que funestamente emergiram em momentos de graves crises políticas na história latino-americana.

Os aportes da pesquisa empírica sobre as atitudes políticas no país deram conta do conjunto de valores que se desenvolveram entre os venezuelanos no período democrático e que colaboraram para a sua continuidade na Venezuela (BALOYRA e MARTZ, 1979; TORRES, 1978 e 1980; PEREIRA, 1998). Entre esses valores figuram especialmente a partidarização e os valores derivados do processo de socialização política que ajudaram a assentar os mecanismos comportamentais de apoio sistêmico, entre eles a participação eleitoral relativamente alta. A preferência democrática dos venezuelanos cresceu, e apresentou-se relativamente 
forte e sem diferenças muito importantes segundo as variáveis sócio-demográficas (idade, gênero, nível de instrução, renda e classe social) desde 1983, quando a medição das variáveis relacionadas à atitude democrática começou a ser feita de modo padronizado e periódico (PEREIRA, 1998).

Do mesmo modo, a variável auto-posicionamento ideológico no contínuo esquerda-direita, em uma tendência intermitente, teve pouca influência até os anos 1980, mas entre 1993 e 1998 ganhou certa importância, indicando que entre os de esquerda há uma proporção menor de democratas do que entre os de direita. Também veio ocorrendo a relação entre o pertencimento ou a inclinação por partidos e uma maior preferência democrática entre os simpatizantes partidários, do que entre os independentes (PEREIRA, 1998; WELSCH e CARRASQUERO, 1996).

O impacto favorável que esses comportamentos vinham tendo sobre a atitude democrática marcava a aceitação generalizada da democracia entre os diferentes grupos sociais, reduzindo os conflitos devidos às controvérsias em torno de sistemas políticos, em especial depois que a guerrilha esquerdista dos anos 1960 foi derrotada. As pequenas diferenças na atitude democrática dadas pelo auto-posicionamento ideológico definiram uma menor tendência democrática entre os esquerdistas, sem que isso significasse conflitos políticos importantes. Em geral, essa situação mostrou o consenso ganho pela democracia e sua legitimidade alcançada entre os venezuelanos (CODETTA, 1990; MOLINA, 1992).

A partir desse cenário e com base na manutenção da relação da maioria das características sócio-demográficas frente à democracia, o objetivo desta análise é verificar se em 2000 a atitude democrática se manteve forte. Com relação ao contínuo esquerda-direita, é possível que seu impacto sobre a atitude democrática continue sendo observado, devido à tendência esquerdista do partido do governo, o MVR, e de seu principal líder, Hugo Chávez. Do mesmo modo, com o esgotamento do antigo sistema de partidos e a diluição das antigas lealdades partidárias, e sem que houvesse tempo para a solidificação das adesões partidárias, é de se esperar que a influência benéfica que as lealdades tinham sobre a atitude democrática, conforme os estudos registravam anteriormente (PEREIRA, 2001; WELSCH e CARRASQUERO, 1996, p. 62-64), tenham se debilitado, também colaborando para debilitar a consistência da atitude democrática.

As análises anteriores também detectavam ameaças ao apreço democrático, como a justificação de golpes militares em determinadas ocasiões, sem que isso significasse necessariamente apoio a expectativas autoritárias (BALOYRA e MARTZ, 1979; MYERS e O'CONNOR, 1998). Embora esse traço prevaleça no país desde que foi registrado em 1973, não impediu a continuidade da preferência democrática, ainda que possa ter tido importância na exacerbação do descontentamento em momentos críticos, como foi o caso do governo de Carlos Andrés Pérez, quando o golpe de 1992 foi justificado por 59\% de um grupo de entrevistados (MYERS e 
O'CONNOR, 1998, p. 199). Em todo caso, a justificação de determinados golpes de Estado foi um traço atitudinal que se manteve no tempo entre os venezuelanos, e pode ser que não tenha adquirido relevância prática na conduta política pelos efeitos da estabilidade que a democracia adquiriu, expressa nas seguintes características: um sistema partidário institucionalizado e com lealdades fortes, processos eleitorais contínuos e alternância no poder, facilidades institucionais para a representação de amplos setores sociais (representação proporcional), papel distribuidor do Estado, sistema de acordos consensuais (KORNBLITH, 1996; LEVINE, 2001 e 1973; MOLINA, 1998; MOLINA e PÉREZ, 1994, 1996 e 1998; REY, 1991; SALAMANCA, 1997) e a generalizada preferência democrática que a população manifestou claramente desde 1983.

Com o desmantelamento dos mecanismos de acordos políticos, o colapso do Estado provedor, o debilitamento do antigo sistema de partidos e das lealdades que antes o beneficiavam, ocorreu o aumento da desconfiança e do descontentamento político que, junto ao enfraquecimento da orientação exercida pelos antigos partidos sobre uma boa parte da população, fez com que as decisões dos indivíduos ficassem mais sujeitas às contingências políticas (PEREIRA, 1996; MOLINA, 2000). Esse desmonte da engrenagem motivadora das atitudes políticas tem logicamente seus efeitos na apreciação de certos traços políticos que são consubstanciais ao ordenamento democrático, pois precisamente as gestões do governo e os partidos passam a ser responsáveis pelas falhas desse ordenamento perante os olhos da população. Esta, na busca de soluções, passa a acalentar certas valorações não democráticas anteriormente contidas, como a justificação de golpes militares e a aclamação de líderes autoritários, pondo em perigo a continuidade da democracia ou, no melhor dos casos, convertendo-a em simples fachada.

A personalização da política, o aumento dos conflitos (protestos e mobilizações) e fragmentações sociais e políticas que ocorreram especialmente a partir de 2001 são expressões do debilitamento institucional da democracia antes aludido. O surgimento de uma grande lista de novos partidos e inumeráveis associações civis, criadas especialmente para a mobilização (tanto dos setores de situação como de oposição) e que competem pelo espaço político, desfavorece o fortalecimento dos partidos, que sofrem o estigma da desconfiança pois, em grande parte, as novas associações emergem com aclamações antipartidárias. A alteração das regras do jogo político, prejudicando a estabilidade antes existente (LEVINE, 2001), a fragmentação de interesses e a permanente confrontação definem debilidades que levam os grupos e partidos à atração por formas alternativas de poder. 
Daí que o exame da consistência da atitude democrática quanto à percepção sobre ter um governo militar e um líder forte no governo poderia lançar resultados orientadores sobre a força da convicção democrática, que poderia ter sido afetada pela passagem de uma democracia orientada partidariamente a uma democracia em que os indivíduos exigem líderes pessoais. Essa compreensão é importante porque por trás do conjunto de modificações que tendem a ocorrer nos sistemas políticos, devido à inserção do fator personalista ou facções militares no poder, está o processo de desinstitucionalização, que permite que essas novas figuras criem as condições propícias para controlar o processo político com pouca ou nenhuma restrição institucional. Este aspecto é sublinhado por Inglehart (2003, p. 52.53), quando aponta que, nas democracias estáveis, o apoio a figuras autoritárias no governo não é importante, mas em outros países esse apoio passa de 50\%, mesmo quando a simpatia pela democracia é muito alta, o que nos leva, evidentemente, a perguntar sobre a solidez da democracia nesses lugares ${ }^{1}$.

Em conseqüência, encontrar a preferência pelo sistema democrático como melhor sistema de governo, aliado à simpatia tanto por governos com líderes fortes como os militares, revelaria entre os venezuelanos uma visão muito frouxa da democracia, comprometendo sua estabilidade e continuidade. Por outro lado, a preferência pelo sistema democrático como melhor sistema de governo, aliada à rejeição aos governos militares e com líderes fortes, expressaria a força da democracia, propiciando contrapesos em eventos desestabilizadores. É por isso que, em uma perspectiva de fortalecimento democrático, esperar-se-ia obter da análise de consistência democrática uma orientação desfavorável a ter governos militares e com líderes fortes.

O outro aspecto que ajudaria a enfraquecer a democracia é a frágil lealdade que existe tanto com respeito aos velhos partidos como aos novos, os primeiros porque suas velhas lealdades se desgastaram e os segundos porque ainda não têm a força necessária para conseguir lealdades fortes. Anteriormente, em um cenário de fortes lealdades partidárias, o vínculo com os partidos facilitava a adesão democrática no país. Agora, quando os novos partidos obtêm alguma simpatia da população, mesmo que frágil, cabe esperar que essas adesões colaborem também para facilitar a atitude favorável em relação à democracia entre os simpatizantes partidários. Mas também se espera que os simpatizantes partidários, uma vez que estão um pouco mais comprometidos com essas instituições, avaliem governos

\footnotetext{
${ }^{1}$ Embora a porcentagem de indivíduos entrevistados no caso venezuelano, no Estudo Mundial de Valores do ano 2000 (suas características são descritas mais adiante), que mostram simpatia por um líder forte não alcance $50 \%$, mas $48 \%$, de todo modo é uma cifra elevada se se considera o longo tempo de exposição democrática dos venezuelanos, desde 1958 e a sucessão de processos eleitorais para eleger autoridades de governo que prevaleceu desde essa época. Ademais, os momentos de instabilidade vividos nesse período (em especial as tentativas de golpes militares de 1992 e de 2002) provocam a preocupação sobre a profundidade democrática nas atitudes políticas do venezuelano.
} 
militares e com líderes fortes de maneira desfavorável. Embora a origem militar dos que aderem ao partido majoritário, o MVR, possa incidir em uma apreciação mais positiva sobre esses dois aspectos, cabe também presumir que seu acesso ao poder por via democrática tenha força para mitigar essa possibilidade.

Finalmente, outro traço que se une às crises políticas nos países democráticos economicamente subdesenvolvidos, ou em vias de desenvolvimento, são os escassos sucessos socioeconômicos das gestões governamentais que promovem o descontentamento político e debilitam governos e partidos, impedindo sua reeleição (MOLINA, 2001). Enquanto as gestões governamentais não vencerem suas sérias deficiências na resolução de problemas na Venezuela, a superação da confiança nas instituições do país será difícil e pressionará no sentido da busca de líderes fortes que resolvam tais problemas mediante procedimentos autoritários e salvadores (PERELLI, 1995), contribuindo com o apoio à democracia de traços autoritários ${ }^{2}$.

\section{Aspectos metodológicos}

Com o objetivo de explorar as possíveis transformações na atitude democrática dos venezuelanos em $2000^{3}$, analisamos a influência de algumas variáveis independentes: as demográficas (idade, gênero), sociais (nível de instrução e renda), o contínuo esquerda-direita e as simpatias partidárias ${ }^{4}$. Também analisamos sua consistência, considerando a valoração sobre ter um governo

\footnotetext{
${ }^{2}$ Segundo um informe de opinião pública (Consultores 21, 2003), pode-se observar os seguintes dados: em setembro de 2003 , os problemas do país mais mencionados em uma amostra nacional de entrevistados foram o desemprego (38\%) e a situação política (24\%); em 1992 foram a economia (25\%) e a corrupção (23\%); e em 1998 (ano eleitoral) foram a delinqüência (19\%) e o desemprego (17\%). Além disso, nesse mesmo informe, lemos que, em 2003, 62\% dos entrevistados disseram que alguns líderes fortes fariam um bem maior a este país do que muitas leis e discursos. Não se conta com as bases de dados dos estudos de opinião mencionados da empresa Consultores 21.

${ }^{3}$ A atitude democrática em Valores 2000 está medida pela seguinte pergunta: "A democracia é melhor do que qualquer outra forma de governo. Você está muito de acordo (1), um pouco de acordo (2), um pouco em desacordo (3), muito em desacordo (4) com essa afirmação?".

${ }^{4}$ Estas perguntas sócio-demográficas e a do contínuo ideológico estão medidas em Valores 2000 no modo padrão conhecido, da pergunta direta e em escala de 1 a 10 para o caso do contínuo ( $1=$ esquerda e 10=direita). A simpatia partidária está constituída pela recodificação das seguintes perguntas: "Em termos gerais, você usualmente se considera Emeverrista (do MVR), Masista (do Movimento Ao Socialismo, MAS), Pepetista (de Pátria Para Todos, PPT), Causaerrista (da Causa R, LCR), Adeco (de Ação Democrática, AD), Copeiano (do Comitê de Organização Política Eleitoral Independente, COPEI), de Projeto Venezuela, Convergente (de Convergência Nacional), Primeiro Justiça, de Um Novo Tempo, Independente ou o quê?" e: "Em sua condição de independente, você se considera mais próximo a um partido que a outros? Qual?", com o objetivo de incluir tanto os partidários como os independentes pró. partido (os esclarecimentos sobre os nomes dos partidos entre parêntesis são da autora).
} 
militar, ter um líder forte ${ }^{5}$ e a satisfação com a democracia ${ }^{6}$. Os dados provêm do Estudo Nacional de Valores do de 1995 e 2000, a partir de agora denominados Valores 1995 e Valores 2000, respectivamente. A análise estatística é feita com a utilização de tabelas de freqüências, cruzamentos de variáveis e medidas de associação ${ }^{7}$.

\section{A lealdade democrática}

Uma vitória política importante do desenvolvimento democrático, que se seguiu à derrubada da última ditadura do país em 1958, foi a sólida preferência pela democracia que os venezuelanos desenvolveram como parte de sua cultura política e que se manteve alta no país desde 1983 (Tabela 1).

Os dados para 2000 merecem uma consideração à parte, uma vez que a preferência pela democracia entre os entrevistados é esmagadora. Uma explicação para esse resultado é que o fenômeno da liderança de Chávez estimulou um entusiasmo maciço pela democracia, que inclui tanto as pessoas muito descontentes com o regime político anterior como uma parte daquelas de tendência radical que eram resistentes ao sistema democrático. É provável que a ascensão ao poder de um líder radical tenha despertado a confiança de algumas pessoas na possibilidade de obter mudanças no país com a democracia e isso renovou-lhes a credibilidade no regime.

\footnotetext{
5 As perguntas correspondentes às variáveis governo militar e líder forte estão medidas do seguinte modo em Valores 2000: "Vou descrever vários tipos de sistemas políticos e lhe perguntarei o que pensa sobre cada um deles. Por favor, diga-me se seria muito bom (1), bom (2), ruim (3) ou muito ruim (4) para o governo deste país..... Ter um governo militar. ......Ter um líder político forte, que não tenha que se preocupar nem com a Assembléia Nacional, nem com eleições".

${ }^{6}$ A variável satisfação com a democracia está medida pela seguinte pergunta em Valores 2000: "Em geral, você está muito satisfeito, algo satisfeito, pouco satisfeito ou nada satisfeito com a forma em que a democracia se está desenvolvendo em nosso país?"

7 A pesquisa Valores 1995 foi aplicada nacionalmente a uma amostra de 1200 pessoas. Faz parte do estudo mundial de valores de 1995 coordenado pelo prof. Ronald Inglehart. Para o caso venezuelano, colaboraram nesse estudo um grupo de pesquisadores do IEPDP.LUZ, da Universidade Simón Bolívar e a Fundação Polar. O Estudo Nacional de Valores de 2000 foi coordenado pelo grupo venezuelano de pesquisadores RedPol e faz parte do estudo mundial de valores dirigido pelo prof. Ronald Inglehart, da Universidade de Michigan. Foi aplicado pela empresa Datos em dezembro de 2000 a uma amostra nacional de 1200 pessoas. A Rede Nacional de Cultura Política (RedPoL) é composta por um grupo de pesquisa nacional financiado pelo FONACIT (Fundo Nacional de Pesquisas Científicas e Tecnológicas de Venezuela); fazem parte do grupo pesquisadores da área política e pública do Instituto de Estudos Políticos e Direito Público da Universidade de Zulia, do Instituto de Pesquisas Políticas e CENDES da Universidade Central de Venezuela, da Universidade Simón Bolívar e do IESA.
} 
Tabela 1

Evolução da preferência democrática dos venezuelanos, segundo diferentes pesquisas

(1983-2000)

\begin{tabular}{c|ccccc}
\hline $\begin{array}{c}\text { Preferência } \\
\text { democrática }\end{array}$ & $\begin{array}{c}\text { BATOBA } \\
1983(1)\end{array}$ & $\begin{array}{c}\text { IEPDP } \\
1993(2)\end{array}$ & $\begin{array}{c}\text { Valores } \\
1995\end{array}$ & $\begin{array}{c}\text { RedPol- } \\
1998\end{array}$ & $\begin{array}{c}\text { Valores } \\
2000\end{array}$ \\
\hline Democratas & $87 \%$ & $87 \%$ & $86 \%$ & $79 \%$ & $93 \%$ \\
& 218 & 167 & 159 & 309 & 88 \\
Não democratas & $13 \%$ & $13 \%$ & $14 \%$ & $21 \%$ & $7 \%$ \\
& 1.789 & 1.499 & 1.200 & 1.500 & 1.200 \\
\hline
\end{tabular}

(1) A Pesquisa BATOBA 1983 foi criada pelos professores Enrique Baloyra e Arístides Torres e aplicada em novembro de 1983 em 1800 pessoas.

(2) A Pesquisa IEPDP 1993 foi criada por pesquisadores do Instituto de Estudos Políticos e Direito Público (IEPDP) da Universidade de Zulia (Maracaibo, Venezuela) e aplicada em 1500 pessoas entre maio e junho de 1993. Disponível em IEPDP-LUZ.

No período compreendido entre os anos 1970 e 1980, a regularidade democrática foi estimulada pela conjunção de circunstâncias favoráveis, tais como o fim da subversão esquerdista, a industrialização, a expansão urbanística e dos serviços públicos, especialmente saúde e educação, entre outros aspectos modernizantes e geradores de emprego, basicamente financiados pelo gasto público (SALAMANCA, 1997). Desse modo, a reversão e nacionalização petroleira e os grandes investimentos em indústrias básicas trouxeram rendimentos sociais e econômicos importantes para o sistema político.

A estabilidade política foi garantida pela modalidade bipartidária dominante (MOLINA e PÉREZ, 1996) dentro de um sistema consensual de acordos políticos e de conciliação de interesses (REY, 1991; KORNBLITH, 1996; LEVINE, 2001) que gerou condições propícias para a legitimação da ordem política democrática na Venezuela.

Ainda no decorrer dos anos 1990, que foram cenário de grande descontentamento, instabilidades políticas (duas tentativas de golpes militares) e mudanças transcendentes no comportamento político (personalização da política e antipartidarismo), as pesquisas mostravam uma elevada aceitação da democracia, embora com variações relativas. A crescente insatisfação com as gestões de governo não afetava sensivelmente a atitude democrática. 
O desenvolvimento da democracia no país generalizou uma atitude favorável entre a população (TORRES, 1991), constituindo uma valoração positiva intrínseca a essa forma de governo. Contudo, as diferenciações importantes na preferência democrática não estavam influenciadas por características demográficas, sociais ou partidárias (PEREIRA, 1996; 1998).

Contudo, detectaram-se outras influências sobre a atitude democrática (PEREIRA, 2001). Entre 1983 e 1998, a preferência pelo sistema econômico foi uma delas: os que escolhiam o capitalismo eram mais democratas do que aqueles que optavam por economias socialistas e comunistas; e para 1998, a influência da variável auto-posicionamento ideológico no contínuo esquerda-direita se fez presente. Os que se auto-localizavam à direita do espectro ideológico eram mais democratas do que os localizados à esquerda e tais influências apoiavam-se em coeficientes de associação relevantes, apontando a influência da preferência por sistema econômico sobre a preferência democrática. Mas tal contraposição não afetou significativamente a consolidação democrática no país, salvo nos períodos de conflitos provocados pela subversão guerrilheira esquerdista dos anos 1960. Essas circunstâncias refletiam o consenso e a legitimação obtidos pela democracia, mediante a aceitação da ideologia de centro e direita, do capitalismo e do bipartidarismo dominante pela grande maioria da população venezuelana (CODETTA, 1990; MOLINA, 1992).

A existência das influências ideológicas antes expostas permite pensar que a atitude democrática poderia ser muito afetada se essas influências chegassem a se aprofundar. Até agora, a diferenciação esquerda-direita sobre a atitude democrática não afetou de maneira importante o consenso democrático entre os venezuelanos, mas se as divisões entre democratas e não democratas se expandissem em razão da influência de posturas ideológicas poderia ocorrer um debilitamento da preferência democrática no país.

Em 2000, segundo os dados da pesquisa Valores 2000, verifica-se novamente a tendência de não influência significativa das variáveis sócio. demográficas sobre a atitude democrática, tampouco há motivo para pensar que a variável auto-posicionamento no contínuo esquerda-direita esteja alterando os valores da preferência democrática. O cruzamento respectivo resulta significativo a 0.001 , mas não mostra associação relevante, por isso não se pode estabelecer nenhuma influência certa. Os esquerdistas recuperaram, um pouco, seu apreço pela democracia, não obstante sua tendência histórica de serem os menos democratas no contínuo esquerda-direita. No entanto, algo ocorreu que fez com que a influência que essa variável tinha em 1998 tenha sido mitigada em 2000. É de se presumir que a chegada ao poder da nova elite política foi um fator que propiciou a atitude democrática entre todos os grupos ideológicos, inclusive entre aqueles que se mantinham céticos em relação à democracia. Esse entusiasmo poderia estar 
ALMAO, V. P. A consistência democrática na Venezuela em tempos de mudança política

baseado no fato de que, em condições de vigência democrática, fosse possível que uma alternativa política diferente às que haviam dominado o país tivesse chegado ao poder e isso entusiasmou especialmente os esquerdistas, que manifestavam usualmente uma preferência um pouco menor.

De acordo com a pesquisa em pauta, os grupos sociais considerados manifestaram suas preferências pela democracia sem maiores diferenças entre eles, o que permite suspeitar que poderiam ser as circunstâncias políticas contingentes que estivessem provocando o aumento da porcentagem da atitude democrática em 2000 (Tabela 1). É possível que a força posta por Chávez em sua proposta de democracia popular tenha despertado um maior interesse pela democracia entre os grupos que antes não o manifestavam. É por isso que, em 2000, se observa uma cifra muito elevada de preferência pela democracia, o que poderia ser enunciado como um ressurgimento do imaginário democrático no país.

A porcentagem de apoio à democracia continua alta depois de 2000. Em 2003 (CONSULTORES 21, 2003), a preferência democrática alcança 90\% e a porcentagem de pessoas que apóiam a idéia de que o país só tem jeito com uma ditadura militar é de $8 \%$. A julgar por esses dados, o entusiasmo democrático persiste, não obstante a constante agitação política que vive o país e os eventos desestabilizadores ocorridos em 2002 e início de 2003 (golpe de abril e greve geral de dezembro de 2002 a fevereiro de 2003). Além disso, no final de 2003, houve a ativação dos processos conducentes à realização de referendos revogatórios constitucionais em 2004, indicando que o país pode resolver seus problemas sem sacrificar a ordem democrática.

\section{Análise de consistência democrática}

As variáveis básicas para avaliar a consistência democrática são o apoio a governos militares e a líderes fortes autoritários. Entende-se que os democratas devem ter valoração mais negativa a essas possibilidades de governos do que os não democrata, e as formas dessa associação têm direta relação com a preferência democrática (INGLEHART, 2003).

As freqüências da variável "apoio ao governo militar" (Tabela 2) mantêm-se relativamente estáveis entre 1995 e 2000 e prevalece a valoração mais negativa (muito ruim/ruim). Da mesma forma, a valoração favorável de ter um líder forte autoritário mostra um crescimento importante em 2000 em relação a 1995 e ambas captam atitudes não democráticas. Não obstante, se considerarmos as implicações que haveria para a democracia ter um líder forte que não atendesse nem à Assembléia Nacional nem às eleições e ter um governo militar, as diferenças entre uma opção e outra parecem ser de forma e não de conteúdo, pois nos dois 
casos haveria a supressão das instituições políticas fundamentais de um regime democrático. A avaliação positiva de qualquer das duas opções é profundamente antidemocrática, porque ambas apontam para a predisposição de sacrificar os valores políticos fundamentais da democracia, que estão implícitos na pergunta do governo militar, mas explícitos no caso do líder forte, - ou seja, as eleições como mecanismo idôneo para decidir quem governa e o organismo de representação política por excelência das distintas forças que participam da política - o parlamento, aspectos que foram considerados procedimentais básicos da democracia (DAHL, 1999), e que funcionam continuamente no país desde as primeiras eleições do período democrático realizadas em dezembro de $1958^{8}$.

Tabela 2

Freqüência do apoio a governo militar e líder forte

\begin{tabular}{l|cccc}
\hline & \multicolumn{2}{|c}{ Valores 1995 } & \multicolumn{2}{c}{ Valores 2000 } \\
\cline { 2 - 5 } & Governo militar & Líder forte & Governo militar & Líder forte \\
\hline Muito bom/ bom & $26 \%$ & $30 \%$ & $23 \%$ & $48 \%$ \\
Muito ruim/ ruim & $74 \%$ & $70 \%$ & $77 \%$ & $52 \%$ \\
\hline & \multicolumn{2}{|c}{ Total: 1200} & \multicolumn{2}{c}{ Total: 1200} \\
\hline
\end{tabular}

Os cruzamentos entre atitude democrática, governo militar e líder forte autoritário (Tabela 3) apresentam associação em que verifica-se que ser democrata atenua a valoração positiva (muito bom e bom) de ter um governo militar, assim como de ter um líder forte em 1995. São os democratas que menos expressam valoração positiva por qualquer das duas opções. No entanto, a contradição é notória para os grupos de entrevistados que se manifestaram pela democracia como melhor forma de governo e depois aparecem envolvidos em valorações positivas de um governo militar e um líder forte. Evidentemente, esses grupos apresentam uma atitude democrática debilitada, em especial os "democratas militaristas".

\footnotetext{
8 Cabe destacar que essa continuidade foi alterada pela convocação de uma Assembléia Nacional Constituinte, procedimento escolhido pelo novo presidente e pela coalizão partidária que o levou ao poder, para elaborar a constituição de 1999, em lugar de seguir os procedimentos de mudança constitucional de que dispunha a constituição de 1961. Depois da aprovação da nova Constituição, essa Assembléia Nacional Constituinte designou um Conselho Legislativo que assumiu as funções do parlamento e dissolveu o congresso bicameral anterior surgido das eleições de 1998. Finalmente, elegeuse um novo congresso unicameral, agora denominado Assembléia Nacional, depois das eleições de relegitimação de poderes de 2000 .
} 
Mas em 2000 o resultado do cruzamento entre atitude democrática com líder forte (Tabela 3) resulta dramático: não há variações estatisticamente apreciáveis e a identificação democrática não freia a disposição para apoiar um líder forte, pois quase a metade dos democratas expressa valorações positivas quanto a ter um líder que não se preocupe com a Assembléia Nacional, nem com eleições.

\section{Tabela 3}

Valoração sobre ter um governo militar e ter um líder forte, segundo a atitude democrática

1995.2000

\begin{tabular}{|c|c|c|c|c|c|c|c|c|}
\hline & \multicolumn{2}{|c|}{$\begin{array}{l}\text { Governo militar } \\
\text { Valores } 1995\end{array}$} & \multicolumn{2}{|c|}{$\begin{array}{l}\text { Governo militar } \\
\text { Valores } 2000\end{array}$} & \multicolumn{2}{|c|}{$\begin{array}{c}\text { Líder forte } \\
\text { Valores } 1995\end{array}$} & \multicolumn{2}{|c|}{$\begin{array}{c}\text { Líder forte } \\
\text { Valores } 2000\end{array}$} \\
\hline & $\begin{array}{l}\text { Demo } \\
\text { cratas }\end{array}$ & $\begin{array}{c}\text { Não } \\
\text { democratas }\end{array}$ & $\begin{array}{l}\text { Demo } \\
\text { cratas }\end{array}$ & $\begin{array}{c}\text { Não } \\
\text { democratas }\end{array}$ & $\begin{array}{l}\text { Demo } \\
\text { cratas }\end{array}$ & $\begin{array}{c}\text { Não } \\
\text { democratas }\end{array}$ & $\begin{array}{l}\text { Demo } \\
\text { cratas }\end{array}$ & $\begin{array}{c}\text { Não } \\
\text { democratas }\end{array}$ \\
\hline $\begin{array}{c}\text { Muito } \\
\text { bom/ bom }\end{array}$ & $22 \%$ & $51 \%$ & $21 \%$ & $41 \%$ & $26 \%$ & $54 \%$ & $48 \%$ & $50 \%$ \\
\hline \multirow[t]{2}{*}{$\begin{array}{c}\text { Muito } \\
\text { ruim/ ruim }\end{array}$} & $78 \%$ & $49 \%$ & $79 \%$ & $59 \%$ & $74 \%$ & $46 \%$ & $52 \%$ & $50 \%$ \\
\hline & \multicolumn{2}{|c|}{$\begin{array}{c}\text { Casos não válidos: } 93 \\
\text { Somers'd } d_{y x}: 0.292 \\
P<0,0001\end{array}$} & \multicolumn{2}{|c|}{$\begin{array}{c}\text { Casos não válidos: } 60 \\
\text { Somers'd } \mathrm{d}_{\mathrm{yx}} \text { : }-0.202 \\
\mathrm{P}<0,01\end{array}$} & \multicolumn{2}{|c|}{$\begin{array}{l}\text { Casos não válidos: } 91 \\
\text { Somers'd } d_{y x}: 0.282 \\
P<0,0001\end{array}$} & \multicolumn{2}{|c|}{$\begin{array}{l}\text { Casos não válidos: } 83 \\
\text { Somers' } d_{y x}:-0.024 \\
P>0,05\end{array}$} \\
\hline
\end{tabular}

Na busca de alguma relação explicativa dessa associação, não encontramos relações estatisticamente significativas com as variáveis sócio-demográficas, o autoposicionamento ideológico, a simpatia partidária e a satisfação com a democracia, nem em 1995 nem em 2000. Isso pode ter uma leitura trágica para a democracia venezuelana porque indica um processo de sensibilização de boa parte dos distintos grupos da população para a idéia da presença de um homem forte, desrespeitoso de instituições políticas fundamentais, o que poderia debilitar a qualidade da democracia no país. Pode-se entender que o processo de personalização da política, que começou em 1989 no âmbito regional e ganhou força nacional a partir de 1993 (MOLINA e PÉREZ, 1994; VAIDVAS, 1994; MAINGÓN e PATRUYO, 1996), não é contingente, deixou sua seqüela nas atitudes políticas e isso faz prever que, em condições de debilidade partidária, siga seu curso por um tempo porque um dos fatores importantes de contenção, o sistema de partidos, não está operando eficientemente. 
No entanto, pode-se dizer que quem contribui um pouco mais para o aumento da valoração positiva de um líder forte em 2000 são os simpatizantes do partido Movimento Quinta (V) República (MVR), e isso ocorre porque entre seus seguidores há grupos que já estavam encantados com a idéia de ter um líder forte, e conquistaram democratas que agora também se sentem atraídos por essa idéia 9 .

De fato, a variável simpatia partidária ${ }^{10}$ é a única que exerce influência, ainda que baixa ${ }^{11}$, sobre o apoio a um governo militar. A Tabela 4 mostra que, em sua maioria, tanto partidários como independentes tendem a valorizar negativamente ter um governo militar, mas entre os simpatizantes de COPEI, MVR e MAS as porcentagens de valoração positiva são um pouco maiores.

Tabela 4

Valoração de ter um governo militar segundo simpatia partidária. Valores 2000

\begin{tabular}{c|ccccccc}
\hline & MVR & MAS & AD & COPEI & PV & PJ $\begin{array}{c}\text { Indepen- } \\
\text { dentes }\end{array}$ \\
\hline $\begin{array}{c}\text { Muito bom/ } \\
\text { bom }\end{array}$ & $31 \%$ & $32 \%$ & $18 \%$ & $40 \%$ & $16 \%$ & $4 \%$ & $21 \%$ \\
$\begin{array}{c}\text { Muito ruim/ } \\
\text { ruim }\end{array}$ & $69 \%$ & $68 \%$ & $82 \%$ & $60 \%$ & $84 \%$ & $96 \%$ & $79 \%$ \\
\hline
\end{tabular}

Casos não válidos: 240

Associação Cramer's V: $0.158(P<0,001)$

9 Com o cruzamento das variáveis líder forte com atitude democrática, controlado por simpatia partidária, obtém-se que 32\% dos emeverristas democratas valorizam positivamente ter um líder forte. Essa é a maior porcentagem de todos os simpatizantes de partido; em seguida estão os simpatizantes do partido tradicional Ação Democrática (AD) com 11\%. Em 1995, a estrutura partidária era outra e o MVR não existia; segundo a pesquisa Valores 1995, os que mais se manifestaram por um líder forte sendo democratas foram principalmente os independentes e, entre os simpatizantes de partidos, os da $A D$, mas em proporções menores.

10 A distribuição da variável simpatia partidária (incluídos os independentes pró-partido) em Valores 2000 é a seguinte: MVR: 31\% (320); MAS: 2\% (25); AD: 9\% (94); COPEI: 2\% (21); Projeto Venezuela: 3\% (33); Primeiro Justiça: 3\% (28); Outros partidos: 4\% (47); Independentes: 46\% (476); Casos não válidos: 156; Total amostra: 1200.

${ }^{11}$ A variável simpatia partidária contém alguns valores pequenos que no cruzamento com governo militar produzem casas menores que 5 e isso altera a medição do coeficiente de associação assimétrica Lambda. Por isso utiliza-se Cramer's V que, mesmo sendo simétrico, mostra força de associação conhecida a variável dependente. 
ALMAO, V. P. A consistência democrática na Venezuela em tempos de mudança política

Embora a variável simpatia partidária contenha valores muito pequenos que reduzem a confiabilidade da medição oferecida, é pertinente levar em consideração as variações encontradas, porque são coerentes com as características dos partidos envolvidos na diferença relativa referida. Pode-se entender que exista um pouco mais de aceitação de um governo militar entre simpatizantes do MVR (Tabela 4) pela procedência militar desse partido, sua insurgência golpista em 1992 e a atração que exerce sobre os esquerdistas mais radicais. O MAS é um partido tradicionalmente de esquerda, que abriga em seu seio tanto esquerdistas democratas como tradicionais, o que poderia expressar-se no cruzamento das variáveis em consideração. No caso de COPEI, por sua posição mais conservadora e de direita, pode dever-se a simpatizantes do tipo extremistas não democratas.

O preocupante no comportamento exposto está no fato de que o MVR é o partido do governo e, até agora, lidera as adesões partidárias nas medições de identificação partidária12; por tal motivo, encontra-se em situação privilegiada para difundir avaliações que podem colaborar para desativar a representação democrática que alguns venezuelanos elaboraram no processo anterior de socialização e exposição política à ordem democrática do país. Ainda não ocorreram processos fundamentais que desmontem a preocupação pela convicção democrática do partido MVR, como a aceitação de resultados eleitorais e de outros mecanismos de cessação de funções mediante revogação do mandato que contempla a Constituição, quaisquer que sejam seus resultados. Disso depende que se possa definir se o MVR estaria colaborando com o processo de socialização política democrática dos venezuelanos, especialmente com o de seus próprios seguidores.

Não obstante, outras características do MVR também devem ser consideradas, em especial a sujeição personalista que mantém em relação ao seu líder principal, Hugo Chávez, e aos traços hegemônicos que se desprendem de seus militantes procedentes da extrema esquerda e do estamento militar. Tais características dão à conduta do MVR uma complexidade dada pela presença em seu seio de algumas das qualidades típicas dos partidos personalistas e de massas tradicionais, nos quais a dependência passiva do líder e da plataforma ideológica gera vieses autoritários na arena política, que em um sistema político de jogo democrático colabora para elevar os níveis de confrontação e radicalização (PANEBIANCO, 1995, p. 267-300; GUNTHER e DIAMOND, 2001, p. 28; PEREIRA, 2001). Desse modo, o MVR apresenta características internas que complicam seu processo de ajuste democrático. Da superação de tais limitações dependerá também que o MVR afiance sua implantação democrática e assegure sua

\footnotetext{
12 Em um estudo nacional de opinião realizado em setembro de 2003 (CONSULTORES 21, 2003), o grupo de simpatizantes do MVR alcança $23 \%$, seguido pela AD com $11 \%$; o resto dos partidos apresenta simpatias abaixo de $10 \%$.
} 
continuidade no espectro de partidos, para que efetivamente possa colaborar na contenção de tentações autoritárias que melhorem a consistência do apreço dos venezuelanos pela democracia.

Em todo caso, o comportamento encontrado mostra uma diferença importante com respeito a uma valoração conexa à atitude democrática, que remete à existência de um maior apreço por um governo militar entre um conjunto de simpatizantes de partido, inclusive o principal partido de governo, que é necessário continuar avaliando no tempo para poder qualificar com maior propriedade o comportamento observado. Um dos problemas que essa tarefa enfrenta é o multipartidarismo instável (MOLINA, 2000) que se instalou no país a partir de 1993 e que até agora não permitiu que as lealdades partidárias se consolidem no tempo.

\section{Conclusões}

A atitude democrática dos venezuelanos aumentou desde 1983 e, em 2000, adquiriu um inusitado entusiasmo entre certos setores da população que antes eram mais céticos com respeito à democracia. Esta atitude não apresenta diferenças vinculadas a variáveis sócio-demográficas, ideológicas nem partidárias; em termos gerais, isso é benéfico porque indica a inexistência de antagonismos, dados pelas influências das características referidas, que comprometam diretamente a valorização da democracia no país.

Mas a análise de consistência democrática deixou clara a existência de debilidades entre alguns que aceitam a democracia como a melhor forma de governo, mesmo quando tenha problemas. Segundo a pesquisa Valores 2000, a democracia é considerada a melhor forma de governo, mas seus apoiadores também julgam positivo ter um líder forte autoritário, que não respeite a Assembléia Nacional nem as eleições, assim como apóiam um governo militar. A atração por um líder forte autoritário cresceu em 2000 em relação a 1995, o que paradoxalmente diminui o brilho do entusiasmo democrático que a Venezuela apresenta nesse ano. Isso expressa o debilitamento da atitude democrática em momentos em que cresce a personalização da política no país e em que o sistema de partidos apresenta grandes fraquezas, constituindo uma ameaça à democracia porque se trata de predisposições que podem encontrar resolução em momentos de dificuldades, sobretudo numa época de alta fragmentação social e política, como a que vive o país atualmente. 
A Venezuela vem apresentando uma clara vocação democrática desde os anos 1980 e isso foi acompanhado de um amplo rechaço às ditaduras pela falta de liberdade que se associa a elas (PEREIRA, 1998; ZAPATA, 1995; WELSCH e CARRASQUERO, 1996). Mas a nova elite política que chegou ao poder em 1998 trouxe consigo um mundo de representações, dentre elas, os vieses personalistas, a simbologia do militar ligado ao popular e a estigmatização da democracia representativa como governo dos privilegiados, ao qual opõem a democracia participativa, cuja bandeira é a igualdade acima de outros valores políticos. Tudo isso pode estimular a população a uma visão da democracia desfocalizada do plano político, que somente privilegie os mecanismos distributivos, o que pode levar a solidificar predisposições autoritárias no político. Esse tipo de predisposição já apareceu no país na justificação de golpes de Estado em determinadas condições (BALOYRA e MARTZ, 1979; MYERS, 1998); além disso, a idéia do gendarme necessário constituiu uma das bases ideológicas do autoritarismo na Venezuela desde a ditadura de Gómez e a AD justificou sua participação no golpe de estado de 1945 denominando-o "revolução de outubro".

No momento outro perigo encontra-se vinculado ao MVR, instituição importante da democracia na atualidade, que reúne as maiores lealdades entre o conjunto de partidos que refletem adesões partidárias e é o principal partido de governo, cujos simpatizantes não exibem uma força suficiente para alimentar predisposições que estimulem a solidificação da atitude democrática, porque apresentam inclinações para figuras autoritárias que contrastam dentro do conjunto de simpatizantes de partidos e independentes. Em condições de conflito político, uma débil identificação democrática como a que mostra uma parte dos simpatizantes do MVR na análise de consistência democrática feita com a variável governo militar, pode colaborar para estimular saídas autoritárias. No entanto, se o MVR não sucumbir na fragilidade partidária existente, tal como aconteceu com o partido de Caldera, Convergência Nacional, cabe a possibilidade de que supere os obstáculos que interferem em sua inserção democrática e seja mais permeável à aprendizagem democrática; nessas condições, poderia ajudar a fortalecer tanto a atitude democrática de seus seguidores como a do resto do país. 


\section{Referências Bibliográficas}

BALOYRA, E.; MARTZ, J. Political attitudes in Venezuela: societal cleavages and political opinion. Austin: University of Texas Press, 1979.

CODETTA, C. La ideología política del venezolano. Caracas: Coediciones Universidad Simón Bolívar-Congreso de la República, 1990.

CONSULTORES 21. Estudio Perfil 21, n. 56. Caracas: Setembro. 2003. Disponível em: www. globovisión.com. Acessado em: 13-10-03.

DAHL, R. La democracia: una guía para los ciudadanos. Madri: Taurus, 1999.

DIX, R. H. Democratization and the institutionalization of Latin American parties. Comparative Political Studies, v. 24, n. 4, p. 488-511, 1992.

HUNTINGTON, S. Political development and political decay. World Politics, v. 17, n. 3, p. 386-430, abril, 1965.

GUNTHER, R.; DIAMOND, L. Types and functions of parties. In: DIAMOND, L.; GUNTHER, R. (Eds.). Political parties and democracy. Baltimore; London: The Johns Hopkins University Press, 2001.

INGLEHART, R. How solid is mass support for democracy and how can we measure it?. PS Political Science and Politics, Washington D.C., v. 36, n. 1, p. 51-57, Janeiro, 2003.

KORNBLITH, M. Crisis y transformación del sistema político: nuevas reglas y viejas reglas del juego. In: ALVAREZ, A. (Ed.). El sistema político venezolano: crisis y transformaciones. Caracas: U.C.V., 1996. p. 1-31.

LEVINE, D. Conflict and political change in Venezuela. Princeton: Princeton University Press, 1973.

Diez tesis sobre la decadencia y crisis de la democracia en Venezuela. In:

CARRASQUERO, J.; MAINGÓN, T.; WELSCH, F. Venezuela en transición: elecciones y democracia 1998-2000. Caracas: Red Universitaria de Estudios Políticos de Venezuela-CDB Publicaciones, 2001.

MAINGÓN, T.; PATRUYO, T. Las elecciones locales y regionales de 1995: tendencias políticas. Cuestiones Políticas. Maracaibo, Venezuela, n. 16, p. 91-136, 1996. 
MAINWARING, S.; SCULLY, T. R. Introduction. In: . (Eds.). Building democratic institutions: party systems in Latin America. Stanford: Stanford University Press, 1995.

MAINWARING, S. Rethinking party systems in the third wave of democratization: the case of Brazil. Stanford: Stanford University Press, 1999.

MOLINA, J. E. El proceso de consolidación de la hegemonía en Venezuela y sus consecuencias políticas. Cuestiones Políticas, Maracaibo, Venezuela, v. 9, p. 73-81, 1992.

Electoral systems and democratic legitimacy in Venezuela. In: CANACHE, D.;

KULISCHECK, M. Democracy and political change in Venezuela. Wesport, Connecticut: Greenwood Press, 1998.

. Comportamiento electoral en Venezuela 1998-2000: cambio y continuidad. Cuestiones

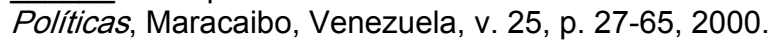

The electoral effect of underdevelopment: government turnover and its causes in LatinAmerican, Caribbean and industrialized countries. Electoral Studies, Guildford, England, v. 20, n. 3, p. 427-446, setembro, 2001.

MOLINA, J. E.; PÉREZ, C. Venezuela: ¿Un nuevo sistema de partidos?. Las elecciones de 1993. Cuestiones Políticas, Maracaibo, Venezuela, v. 13, p. 63-89, 1994.

Los procesos electorales y la evolución del sistema de partidos en Venezuela. In:

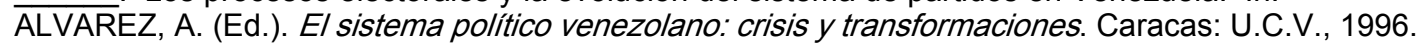

La democracia venezolana en una encrucijada: las elecciones nacionales y regionales de 1998. Cuestiones Políticas, Maracaibo, Venezuela, v. 22, p. 75-106, 1998.

MYERS, D. J.; O'CONNOR, R. E. Support for coups in democratic political culture: a Venezuelan exploration. Comparative Politics, New York, v. 30, n. 2, p. 193-212, 1998.

PANEBIANCO, A. Modelos de partido: organización y poder en los partidos políticos. Madri: Alianza Editorial, 1995.

PEREIRA, V. La lealtad democrática de los venezolanos en los críticos años 90 . Cuadernos del CENDES. Caracas, Venezuela, v. 33, p. 91-103, 1996.

1998.

La democracia mínima de los venezolanos. Politeia. Caracas, Venezuela, v. 21, p. 45-62, 
Cambio político radical y actitud hacia la democracia en Venezuela. In: CARRASQUERO, J.; MAINGÓN, T.; WELSCH, F. Venezuela en transición: elecciones y democracia 1998-2000. Caracas: Red Universitaria de Estudios Políticos de Venezuela-CDB Publicaciones, 2001.

. Movimiento V República. In: ALCÁNTARA, M.; FREIDENBERG, F. (Eds.). Partidos políticos de América Latina: Países Andinos. Salamanca, España: Ediciones Universidad de Salamanca, 2001.

PERELLI, C. La personalización de la política: nuevos caudillos, "outsiders", política mediática y política informal. In: PERELLI, C.; PICADO, S.; ZOVATTO, D. (Comp.). Partidos y clase política en América Latina en los 90. San José, Costa Rica: IIDH-CAPEL, 1995.

REY, J. C. La democracia venezolana y la crisis del sistema populista de conciliación. Estudios Políticos. Madri, v. 74, p. 533-578, 1991.

SALAMANCA, L. Crisis de la modernización y crisis de la democracia en Venezuela. Caracas: U.C.V.-I.L.D.I.S., 1997.

TORRES, A. ¿Son los copeyanos distintos a los adecos?. Auténtico, Caracas, n. 66, 11 de setembro, 1978.

. La 'experiencia' política en una democracia partidista joven. El caso de Venezuela. Politeia. Caracas, Venezuela, v. 9, p. 263-285, 1980.

La evolución hacia el sistema político en Venezuela. In: COPRE. Venezuela, Democracia y Futuro. Caracas: COPRE. 1991. p.173-186

VAIDVAS, H. Las elecciones de 1993 y sus efectos sobre los partidos políticos y el sistema de partidos. Cuestiones Políticas. Maracaibo, Venezuela, v. 13, p. 91-103, 1994.

WELSCH, F.; CARRASQUERO, J. ¿Desconsolidación de la democracia en Venezuela? Rendimiento y legitimidad normativa. Cuestiones Políticas. Maracaibo, Venezuela, v. 16, p. 45-69, 1996.

ZAPATA, R. Los valores del venezolano. Caracas: Conciencia 21, 1995. 